\title{
Modeling of potential habitat suitability of (1) comesuat Hippocamelus bisulcus: effectiveness of a protected areas network in Southern Patagonia
}

Yamina Micaela Rosas ${ }^{1}$, Pablo L. Peri', Alejandro Huertas Herrera ${ }^{1}$, Hernán Pastore ${ }^{3}$ and Guillermo Martínez Pastur ${ }^{1 *}$

\begin{abstract}
Introduction: Huemul (Hippocamelus bisulcus Molina) is the most threatened flag species of Southern Patagonia, where conservation efforts were not effective to avoid the retraction of its distribution area. Habitat quality modeling can assist to design better management strategies for regional conservation planning. The objective was to elaborate one habitat suitability map for huemul, defining the environmental characteristics at landscape level, and determining the distribution of the suitable habitat inside the current natural reserve network.

Methods: We used a database of 453 records and explored 40 potential explanatory variables (climate, topographic, and landscape variables including human-related ones) to develop one habitat suitability map using the Environmental Niche Factor Analysis (ENFA) for Santa Cruz province (Argentina). We combined the outputs in a GIS project using different shapes, including the current natural reserve network.

Results: We defined the potential habitat for huemul, where forest edges and ecotone zones (e.g., mainly alpine environments) were the most important environmental variables, as well as some forest types (e.g., Nothofagus pumilio). Habitat losses were found in the extreme potential distribution areas (northern and southern areas), probably related to the increasing ranch activities. The current natural reserve network maintains approximately half of the huemul potential habitat in Santa Cruz province, where National Parks presented the similar conservation importance than the Provincial natural reserves.
\end{abstract}

Conclusions: Habitat suitability model for huemul can be used as a decision support system for new management strategies at different landscape levels to improve the current conservation efforts.

Keywords: Nothofagus forests, ENFA, Habitat loss, Conservation, Species requirements

\section{Introduction}

One of the most important issues in the management and conservation planning is the knowledge of habitat requirement for a target species (Tan et al. 2016; Villero et al. 2017). These requirements allow to define living and environmental conditions that limit the species distribution (Acevedo et al. 2010; Moreau et al. 2012). In many cases, the current habitat distribution for rare or endangered species diminished due to several factors related to human

\footnotetext{
* Correspondence: gpastur@conicet.gov.ar

${ }^{1}$ Laboratorio de Recursos Agroforestales, Centro Austral de Investigaciones Científicas (CONICET), Houssay 200, Ushuaia 9410, Tierra del Fuego, Argentina Full list of author information is available at the end of the article
}

(e.g., forestry, agricultural lands, ranching, mining) or climate change factors (Jiménez-Valverde et al. 2008; Newbold 2010; Mikoláš et al. 2017). For an effective management and conservation strategies, the potential habitat distribution of the target species allows to (i) analyze the effectiveness of the current network of protection areas, (ii) improve the regional connectivity by setting up new conservation areas, and (iii) identify areas for potential restoration or reintroduction programs (Klaret al. 2008; Gilbert-Norton et al. 2010; Zheng et al. 2016). Besides this, potential habitat distribution also allows to identify synergies and trade-offs with other economic activities (Luque et al. 2011; Carpentier et al. 2017; Martínez Pastur et al. 2017). 
Natural reserves should be created to preserve unique landscape values or to conserve unique habitats (Barr et al. 2016); however, in Patagonia (Argentina), most of the natural reserves were created following other criteria (e.g., frontline policy strategies with countries). For this, it is necessary to know the protection effectiveness of these reserves to conserve the local fauna. The strategy of landsparing has been considered ineffective for species with greater habitat requirements or with partial migration among seasons (Todd et al. 2016; Coetzee 2017). On the contrary, the land sharing strategy integrates private lands with governmental areas under economic uses (e.g., forestry or mining) into the conservation planning (Gustafsson et al. 2012; Martínez Pastur et al. 2016, 2017) and could effectively preserve the local fauna. For this, assessment habitat suitability is a crucial step to choose areas for setting up new reserves.

There has been an increasing interest in the use of spatially explicit habitat models over the last decades (Guisan and Zimmermann 2000). Geographic Information Systems (GIS) with multivariate models has been used to understand both species-habitat associations and to derive habitat suitability maps (HSM) (Hirzel et al. 2002; Braunisch et al. 2008). Habitat suitability modeling relates a species' occurrence to a set of environmental variables to model its ecological niche and predict its potential distribution (Soberón 2007; Hirzel and Le Lay 2008). This fits a mathematical function which can be interpolated or extrapolated to areas with a lack of information for the focus species (Guisan and Zimmermann 2000). One of the most innovative uses is related to biodiversity conservation including areas for endangered species translocations and to design new natural reserves focused on single (Peterson 2006) or multiple species (Poirazidis et al. 2011; Martínez Pastur et al. 2016). There is an increasing use of predictive models applied to rare and endangered species (e.g., Thorn et al. 2009; Zheng et al. 2016; Quevedo et al. 2017); however, it is still limited by the lack or absence of quantified data, especially in low populated areas or developing countries.

In Argentina, one endemic medium-sized deer (Hippocamelus bisulcus Molina, commonly named as huemul) is the most endangered species of Patagonia (Black-Decima et al. 2016), being the flag species for several conservation programs (Flueck and Smith-Flueck 2006; Smith-Flueck et al. 2011; Vidal et al. 2011). Some authors sustain that this species presented a marked decrease in its geographical distribution due to a combination of several factors, e.g., habitat loss, trade-offs with domestic species (cattle or dogs), poaching, malnutrition, and infectious disease (Díaz and SmithFlueck 2000; López-Alfaro et al. 2012; Corti et al. 2011, 2013). Several conservation efforts in Southern Patagonia had been conducted without clear knowledge about species habitat requirement and/or the effectiveness of the current natural reserve network (National and Provincial reserves)
(Frid 2001; Vila et al. 2006; Luque et al. 2011; Martínez Pastur et al. 2016).The objective of this study was to elaborate a potential HSM for huemul in Santa Cruz province (Argentina). Additionally, we want to answer the following questions: (i) which are the main environmental requirements for huemul? (ii) is the potential habitat suitability area coincident with the current distribution of the species? and (iii) where are the suitable distribution areas in the natural reserve network? With these questions, we want to understand the huemul ecological requirements and to know if the species actually occupy the entire potential habitat along its historical distribution according to archeological and historical references. We also want to characterize the protection status of the species considering the conservation strategy of the National and Provincial Governments.

\section{Methods}

Study area

The study was carried out in the entire Santa Cruz province (Argentina) $\left(46^{\circ} 00^{\prime}-52^{\circ} 30^{\prime} \mathrm{S}, 66^{\circ} 00^{\prime}-73^{\circ} 00^{\prime} \mathrm{W}\right)$ covering $243,943 \mathrm{~km}^{2}$. Total inhabitants are 320,469 (year 2015) living in 37 localities (cities and small towns). Lakes are mainly located at the base of the Andes Mountains and main rivers flow from $\mathrm{W}$ to $\mathrm{E}$ to the Atlantic Ocean. Ice fields and the mountains ( $\mathrm{N}$ to $\mathrm{S}$ direction) define relief and climate, generating a rainfall gradient from W to E. National Parks and Provincial Reserves mainly preserve forests in the Andes Mountains. Some reserves were created to protect beautiful landscapes (e.g., Los Glaciares National Park) or to preserve unique biodiversity (e.g., Perito Moreno National Park and Tucu-Tucu Provincial Reserve). Finally, the main ecological areas are dominated by steppe grasslands and shrublands, while Nothofagus forests and alpine vegetation occupy a narrow strip along the mountains (Fig. 1).

\section{Field observation database of huemul}

Records of presence of huemul were based on database of Administración de Parques Nacionales (APN) of Argentina surveyed during different studies (Vila et al. 2006; Flueck and Smith-Flueck 2011), including the location (latitude and longitude) of each direct sight of individuals or indirect (antlers, bones, feces, or foot prints) records (since 1997). These records were integrated into a geographical information system (GIS) using ArcMap 10.0 software (ESRI 2011). We determined the percentage of observations according to (i) ecosystem types (forests and open lands), (ii) forest types (Nothofagus pumilio, N. antarctica, or mixed evergreen forests), (iii) the difference between percentage of huemul field observations in each forest type and the percentage of each forest type area of Santa Cruz province, (iv) field observation distances of huemul from the forest edge (inside and outside the forests) expressed as the percentage of the total data, and (v) the difference between percentage of total field observations at each elevation and 


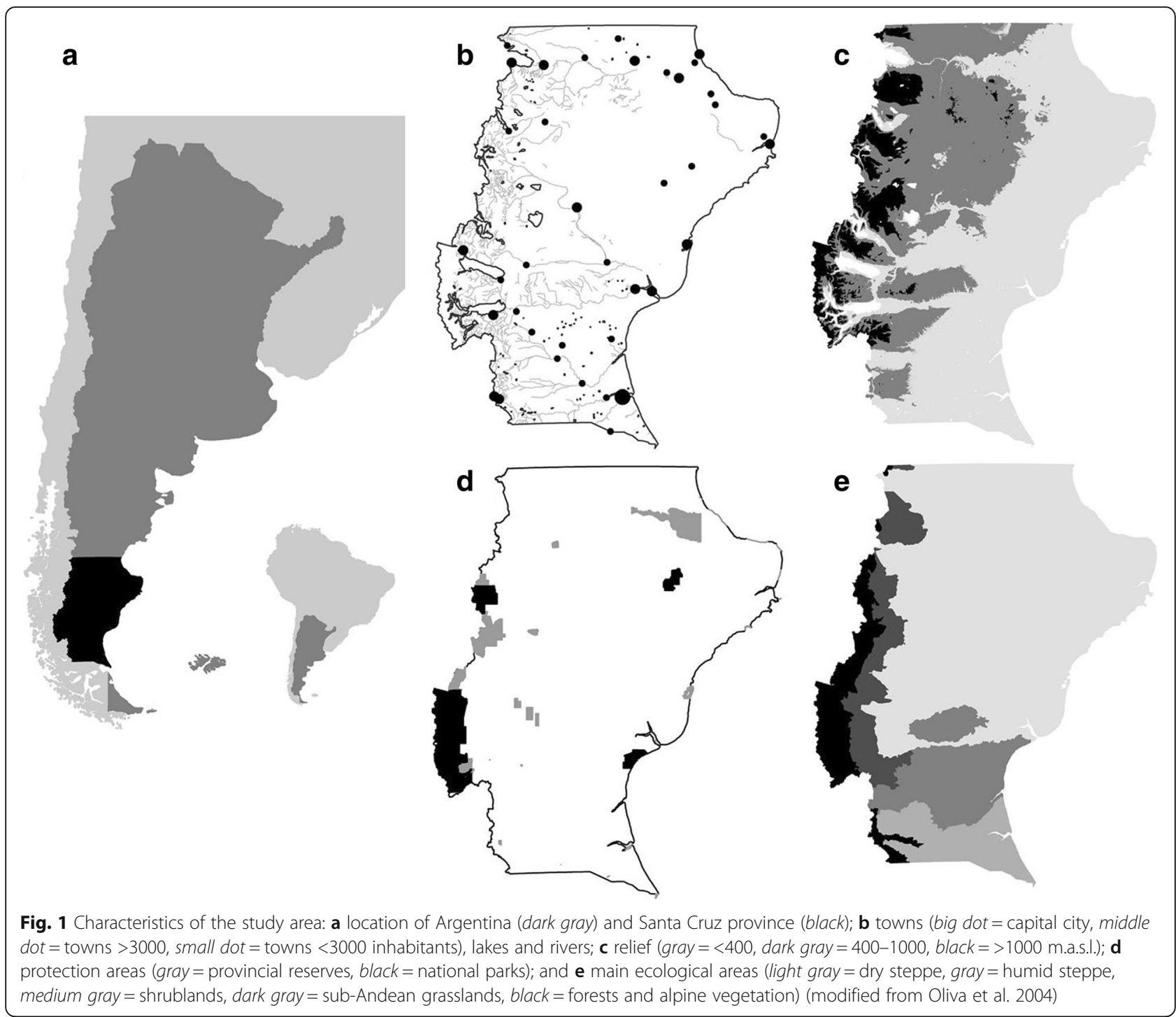

the percentage of field observations in each ecosystem type (forests and open lands).

\section{Potential HSM of huemul}

For modeling a potential HSM, climatic, topographic, and landscape variables were used by exploring 40 potential explanatory variables (Appendix 1) rasterized at $90 \times 90$ m resolution grid using ArcMap 10.0 software (ESRI 2011). Climatic variables $(n=21)$ (Hijmans et al. 2005) included temperature, precipitation and annual, monthly or seasonal indexes, as well as global potential evapo-transpiration and global aridity (Zomer et al. 2008). The topography variables $(n=8)$ were defined using GIS and the shuttle radar topography mission data (Farr et al. 2007) which produced the highest resolution digital elevation model. With these images, we defined elevation, slope, and aspect grids, where aspect was calculated as sine and cosine function of the north magnetic direction (E-W and N-S) (Jenness 2007). The other variables included distance to (i) main localities (cities and towns), (ii) lakes, (iii) main rivers, and (iv) routes (national and provincial). These distances (Euclidean) were calculated using shapes obtained from the Sistema de Información Territorial (SIT Santa Cruz, http://spm.sitsantacruz.gob.ar). Finally, landscape metrics $(n=11)$ including (i) forest type covers (N. pumilio, $N$. antarctica, or mixed evergreen forests) of Santa Cruz province; (ii) forest metrics derived from Fragstats software (McGarigal et al. 2012) associated to edge density, total core area, and largest patch index for the total forest cover; (iii) the normalized difference vegetation index (NDVI) (ORNL DAAC, 2008); (iv) net primary productivity (NPP) of year 2015 (Zhao and Running 2010); and (v) desertification index (Del Valle et al. 1998).

Ten variables were selected for modeling based on Pearson's correlation indices obtained from paired analyses. We 
selected those variables with the lower correlation among the variables of each group. This selection included three climate, three topography, and four landscape variables. The climate variables were annual mean temperature (AMT), minimum temperature of the coldest month (MINCM), and mean annual precipitation (AP). The topography variables were slope (SLO), cosine aspect (ASP), and distance to rivers (DR). Finally, the landscape variables were NPP, desertification index (DES), total forest cover (TF), and edge density (ED).

Using Environmental Niche Factor Analysis (ENFA, Hirzel et al. 2002) in the Biomapper 4.0 software (Hirzel et al. 2004), we elaborated the potential HSM for huemul. ENFA compares the eco-geographical predictor distribution for a presence data set consisting of locations where the species has been detected with the predictor distribution of the whole area (Hirzel et al. 2001). ENFA calculates a measure of habitat suitability based on an analysis of marginality (how the species' mean at each location differs from the mean of all sites in the study area) and environmental tolerance (how the species' variance at each location differs with the global variance of all sites) or specialization (defined as 1/tolerance) (Martínez Pastur et al. 2016). We used a distance of geometric-mean algorithm to perform the analyses, which provides a good generalization of the niche (Hirzel and Arlettaz 2003).

The obtained HSM had scores that varied from 0 (minimum habitat suitability) to 100 (maximum), and it was evaluated by a cross-validation process (Boyce et al. 2002; Hirzel et al. 2006) through (i) the Boyce index $(B)$ which indicates how consistent are the model's predictions with the distribution of presences in the evaluation dataset $(-1$ to 1 ), (ii) the proportion of validation points $(P)$, (iii) the continuous Boyce index (Bcont), (iv) the absolute validation index $(A V I)$ defined as the proportion of validation cells with habitat suitability $(0-1)$, and (v) the contrast validation index $(C V I)$ defined as $A V I-A V I>50$ which indicates how much the model differs from a random model (0-0.5) (Hirzel and Arlettaz 2003; Hirzel et al. 2004, 2006). The obtained HSM was reclassified as unsuitable areas (0$40 \%)$, low potential habitat suitability (40-50\%), medium potential habitat suitability (50-70\%), and high potential habitat suitability (70-100\%). We defined these thresholds based on Martínez Pastur et al. (2016) proposals.

\section{Evaluation of the potential HSM of huemul}

The environmental characteristics of the potential HSM of huemul were calculated for 21 climate and two topographic variables by comparing mean values and standard deviation for the entire province, and the outputs of the different map qualities (unsuitable, low, medium, and high) into a GIS project. In a second analysis, we compared the database from the field observations as a proxy of current distribution and the HSM outputs as the potential distribution of the species. For this, to determine the approximate current distribution of the species, we calculated a buffer of $9 \mathrm{~km}$ ratio for each observation point of the database into a GIS project based on the maximum movement reported for the annual home range (Saucedo et al. 2004; Vila et al. 2006; Gill et al. 2008). The addition of all the individual areas defined the current distribution area of the species. This assumption of our analyses may not include all the exiting huemul populations that were included in the database, so our analyses may potentially underestimate the current distribution area. This area was crossed with the different HSM qualities to identify habitat loss and potential new conservation areas. We understand habitat loss as the suitable areas of HSM without current presence of the species. In a third analysis, we determined the distribution of the HSM outputs according to its quality inside and outside the natural protection areas (Provincial and National Reserves).

\section{Results}

\section{Field observation database of huemul}

Huemul used the forests and the open environments indistinctively when field observations were analyzed into a GIS (52 and 48\%, respectively) (Fig. 2a). However, each forest type showed different preferential uses by the species (Fig. 2b, c). When we compared the record occurrences and each forest type, we found that (i) $71 \%$ of the forests in Santa Cruz province belonged to $N$. pumilio forest type where $88 \%$ of the huemul observations occurred indicating a higher preference $(+17 \%)$; (ii) $26 \%$ of the forests belonged to $N$. antarctica type where $10 \%$ of the huemul observations were detected, showing a lower expected uses $(-16 \%)$; and (iii) $3 \%$ of the forests belonged to mixed evergreen forest type with $2 \%$ of the huemul observations, showing as slightly lower expected uses $(-1 \%)$. Finally, the field observation distances from the edge (forest and open lands) showed a major concentration in the first $200 \mathrm{~m}$ buffer area (38\% in the inner edge and $29 \%$ in the outside edge of the forests) (Fig. 2d). The presence of the huemul drastically decreased at higher distances, reaching up to $800 \mathrm{~m}$ inside the core forests and $>1000 \mathrm{~m}$ in the steppe. Finally, the difference between percentage of total field observations at each elevation and the percentage of field observations in each ecosystem type (forests and open lands) showed a greater preference of huemul for forest environments between 400 and 800 m.a.s.l., while open lands were preferred by huemul at lower (200-400 m.a.s.l.) or at higher elevations (>1000 m.a.s.l.) (Fig. 2e).

\section{Potential HSM of huemul}

The ten selected variables used for modeling (Table 1) were chosen for their Pearson's correlation index among the variables of each group type (climate, topography, or landscape). Climate variables presented correlation indexes between 0.25 and 0.59 . Some climate variables were greatly 


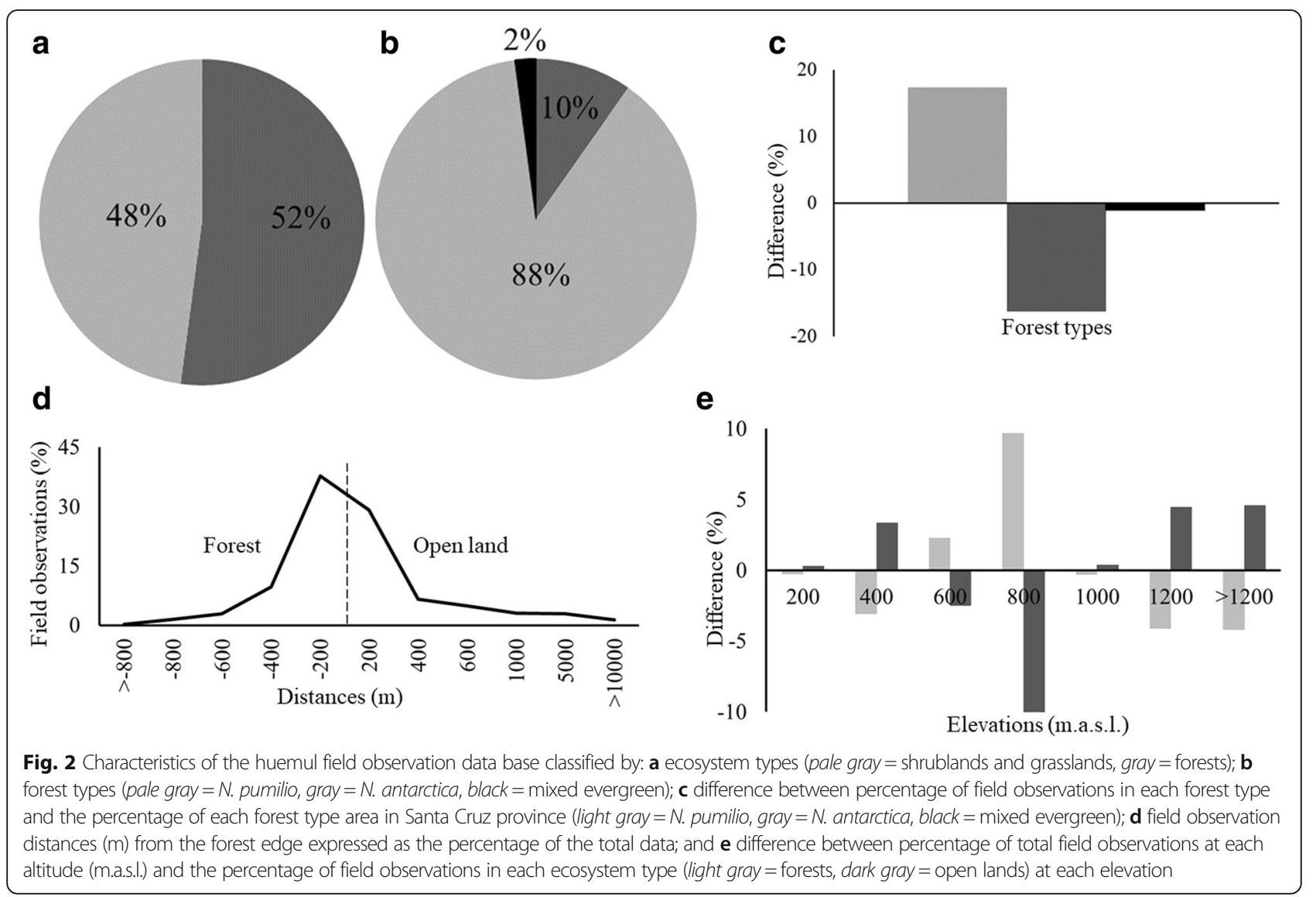

influenced by the topography (e.g., temperature was influenced by the aspect with a correlation index of 0.80 ) or landscape variables (e.g., temperature influence over desertification index with 0.91 ). Topography variables presented correlation indexes between 0.24 and 0.51 , and aspect also influenced desertification index with 0.75 . Finally, landscape

Table 1 Correlation indices among the variables included in the modeling of the habitat suitability of huemul

\begin{tabular}{llllllllll}
\hline Variable & MINCM & AP & SLO & ASP & DR & NPP & DES & ED & TF \\
\hline AMT & 0.25 & 0.43 & 0.29 & 0.80 & 0.52 & 0.67 & 0.91 & 0.02 & 0.02 \\
MINCM & & 0.59 & 0.51 & 0.54 & 0.38 & 0.35 & 0.30 & 0.14 & 0.09 \\
AP & & & 0.66 & 0.58 & 0.38 & 0.46 & 0.35 & 0.30 & 0.22 \\
SLO & & & & 0.43 & 0.24 & 0.32 & 0.26 & 0.27 & 0.19 \\
ASP & & & & & 0.51 & 0.65 & 0.75 & 0.10 & 0.06 \\
DR & & & & & & 0.33 & 0.49 & 0.01 & 0.00 \\
NPP & & & & & & 0.54 & 0.31 & 0.30 \\
DES & & & & & & & 0.05 & 0.04 \\
ED & & & & & & & & & \\
\hline
\end{tabular}

AMT annual mean temperature $\left({ }^{\circ} \mathrm{C}\right)$, MINCM minimum temperature of the coldest month $\left({ }^{\circ} \mathrm{C}\right)$, AP mean annual precipitation $\left(\mathrm{mm}\right.$ year $\left.{ }^{-1}\right)$, SLO slope (\%), $A S P$ north-south aspect (cosine of degrees), DR distance to rivers $(\mathrm{km}), N P P$ net primary productivity $\left(\mathrm{gr} \mathrm{C} \mathrm{m}^{-2}\right.$ year ${ }^{-1}$ ), DES desertification degree, ED forest edge density $\left(\mathrm{m} \mathrm{ha}^{-1}\right)$, TF forest occurrence variables were the group with lower correlation indexes (0.04-0.54).

The selected variables were used for the ENFA analysis, being reduced to four factors that explained $94 \%$ of the variance (Table 2). The marginality factor (first axis) explained $7.3 \%$ where forest cover $(0.59)$ and forest edge density (0.59) were the variables with greater influence. In contrast, rainfall, NPP, and slope presented a marginal influence (0.27-0.35). The presence of huemul in the cells with greater values of these variables differed from the mean values in the region due to a large study area used (entire Santa Cruz province) for the modeling. The specialization factors (axes 2-4) explained $75.5,6.0$, and $4.6 \%$, where (i) in axis 2 , temperature $(-0.94)$ was the main influence variable, and extreme temperature (MINCM) presented a marginal influence (0.32); (ii) in axis 3, MINCM (-0.92) was the main influence variable, and distance to rivers presented a marginal influence (-0.34); and (iii) in axis 4 , temperature $(-0.65)$, distance to rivers $(0.59)$, and desertification index $(0.34)$ were the variables with greater influence, and rainfall and aspect presented a marginal influence $(0.28$ and -0.14$)$. Global marginality presented a high value (4.87) indicating that huemul habitat greatly differed from the average studied conditions. However, the calculated tolerance was 0.68 , which suggests that the huemul is not too demanding on its living environment. 
Table 2 Model outputs of the habitat suitability of huemul, where brackets in the eigenvalues present the specialization values

\begin{tabular}{lllll}
\hline Eigenvectors & E1 & E2 & E3 & E4 \\
\hline AMT & 0.03 & -0.94 & -0.20 & -0.65 \\
MINCM & -0.05 & 0.32 & -0.92 & 0.05 \\
AP & 0.35 & 0.08 & -0.07 & 0.28 \\
SLO & 0.27 & 0.00 & -0.01 & -0.09 \\
ASP & 0.08 & -0.01 & 0.02 & -0.14 \\
DR & 0.00 & -0.01 & -0.34 & 0.59 \\
NPP & 0.31 & 0.02 & -0.01 & 0.02 \\
DES & -0.06 & -0.06 & -0.02 & 0.34 \\
ED & 0.59 & 0.02 & -0.02 & -0.04 \\
TF & 0.59 & 0.00 & 0.00 & -0.01 \\
Eigenvalues & $1.56(0.07)$ & $16.18(0.75)$ & $1.29(0.06)$ & $0.98(0.05)$
\end{tabular}

AMT annual mean temperature $\left({ }^{\circ} \mathrm{C}\right), \operatorname{MINCM}$ minimum temperature of the coldest month $\left({ }^{\circ} \mathrm{C}\right), A P$ mean annual precipitation $\left(\mathrm{mm}^{2}\right.$ year $\left.{ }^{-1}\right)$, SLO slope (\%), $A S P$ north-south aspect (cosine of degrees), DR distance to rivers ( $\mathrm{km}$ ), NPP net primary productivity $\left(\mathrm{gr} \mathrm{C} \mathrm{m}^{-2}\right.$ year $\left.^{-1}\right), D E S$ desertification degree, $E D$ forest edge density $\left(\mathrm{m} \mathrm{ha}^{-1}\right), \mathrm{TF}$ forest occurrence

Potential HSM for huemul showed a wide latitudinal distribution $\left(46^{\circ}-52^{\circ} \mathrm{S}\right)$ located mainly at the base of the Andes mountain (in the forest and alpine vegetation ecological area) (Figs. 3 and 1e) and close to lakes and lagoons. In the northern area (Fig. 3a) of the province presented a marginal and discontinuous potential habitat with two nucleus (El Portezuelo at $46^{\circ} 03^{\prime} 01^{\prime \prime}$ ' $\mathrm{S}$ and $71^{\circ}$ $39^{\prime} 59^{\prime \prime}$ 'W, and Monte Zeballos at $46^{\circ} 51^{\prime} 56^{\prime \prime} \mathrm{S}$ and $71^{\circ}$ $53^{\prime} 24^{\prime \prime}$ W). The central area (Fig. 3b-d) showed a continuous high potential habitat distribution. Finally, the southernmost area (Fig. 3e) was separated from the central distribution decreasing the potential habitat. This included marginal forested areas with lower influence of the Andes Mountains (e.g., central hills close to Stag River and Rio Turbio localities). The obtained HSM showed good validation statistics: (i) the explained information was 96\%, (ii) the Boyce index was 0.92 which indicates that the model predictions are consistent with the presence distribution of the field observation dataset, (iii) $P(B$ $=0$ ) was 0.08 and Bcont (20) was 0.72 which indicates a good statistics for the cross validation analyses of the model, and (iv) $A V I$ was 0.50 and $C V I$ was 0.50 which indicate that the model predictions were very consistent with the evaluation datasets since $50 \%$ of evaluation records were enclosed in the core area.

\section{Environmental characteristics of the HSM of huemul}

The characteristics of the climatic and topographic variables according to the HSM developed for the entire study area and the habitat quality (low, medium, high) determined patterns of change among variables and also determined the potential habitat suitability for huemul (Table 3). Temperature (AMT) influenced habitat suitability by increasing the quality at lower temperatures compared to the average for the entire province $\left(7.8{ }^{\circ} \mathrm{C}\right)$. The optimum HSM was $5.5{ }^{\circ} \mathrm{C}$ and the marginal response occurred at $4.9{ }^{\circ} \mathrm{C}$ determining unsuitable conditions at lower and higher temperatures. The other related temperature variables followed the same pattern (MAXWM, MINCM, MTWEQ, MTDQ, MTWAQ, MTCQ). Seasonal and daily variations of temperature (MDR and TAR) also influenced habitat distribution of huemul, where lower variations were more adequate for the species. However, isothermality (ISO) did not greatly influence HSM (near $47 \%$ for the habitable areas and $46 \%$ for the entire study area). Rainfall (AP) also influenced habitat suitability by increasing the quality with precipitation (mean value for the study area of $246 \mathrm{~mm}$ year -1 , optimum HSM of $621 \mathrm{~mm} \mathrm{year}^{-1}$, and marginal of $610 \mathrm{~mm}$ year $^{-1}$ ). The other related rainfall variables followed the similar pattern (PWEM, PDM, PWEQ, PDQ, PWAQ, PCQ). Seasonality of temperature and rainfall (TS and PS) was lower at higher quality habitat for huemul $\left(3.7^{\circ} \mathrm{C}\right.$ for TS and $17.8-18.8 \%$ for PS in habitable environments). The other studied climatic indexes (EVTP and GAI) followed the combined patterns of the temperature and rainfall variables, where the HSM values decreased with the evapotranspiration (study area $808 \mathrm{~mm}_{\text {year }}^{-1}$, while HSM optimum at $664 \mathrm{~mm} \mathrm{year}^{-1}$, and marginal at $657 \mathrm{~mm}$ year $^{-1}$ ) and the aridity (study area 0.3 , while HSM values reached 0.9). HSM values increased in the mountain environments with suitable values above 600 m.a.s.l. and decreased in quality at lower or higher elevations (marginal habitats reaching up to 740 m.a.s.l.). The slope was also related to the topography, increasing the habitat quality at higher slopes (up to 13\%) compared to the regional values (5\%).

The characteristics of the climatic and topographic variables according to its quality allowed us to understand the marginality and tolerance values obtained in the HSM modeled. Thus, habitat was restricted to specific locations closely related to climate and topographic variables which also influenced other ecosystems (e.g., forests and alpine vegetation) (Fig. 1). Beside this, the environmental variables of the different habitat suitability did not greatly vary among the different quality categories (Table 3).

\section{Comparison of potential and current distribution of huemul} Potential habitat for the species identified by HSM reached to $4734 \mathrm{~km}^{2}$, where $1700 \mathrm{~km}^{2}$ belonged to low, $1540 \mathrm{~km}^{2}$ to the middle, and $1494 \mathrm{~km}^{2}$ to high quality (Table 4). When the HSM outputs were compared with current distribution of the species, this area represented $39 \%$ of the potential habitat (33\% of low, $39 \%$ of the middle, and $47 \%$ of high quality areas). The field observation points were concentrated in two main areas (Fig. 4), one in the centernorth (Fig. 3b) and one in the center-south (Fig. 3c, d). The first area was located in the Perito Moreno National Park, while the second was located in Los Glaciares National 


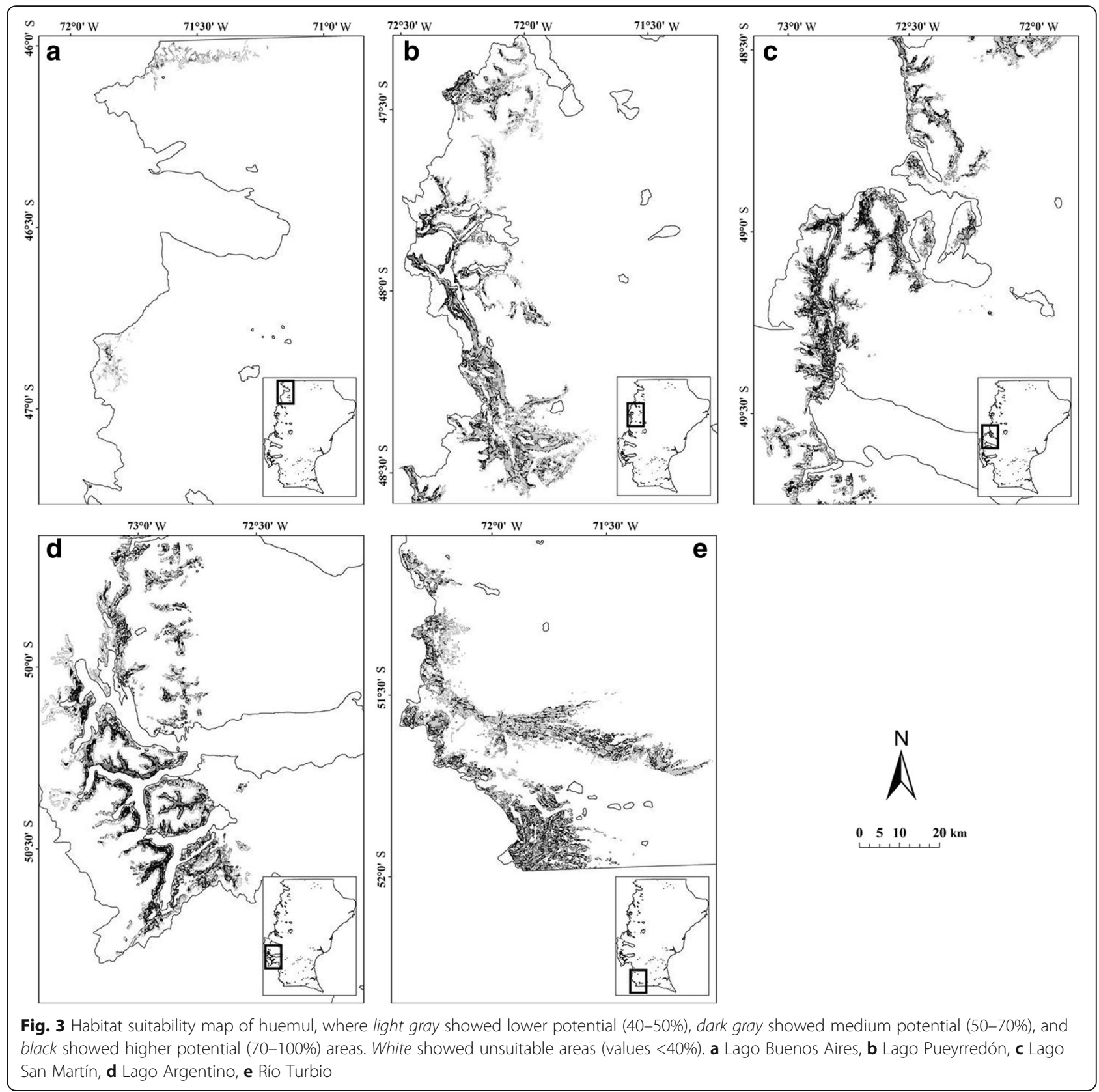

Park and Lago del Desierto Provincial Reserve, where 61\% of the potential distribution area did not present any data for the species since year 1997. These areas were located in the extreme north and south, and close to Perito Moreno National Park and Lago del Desierto Provincial Reserve. Elevation greatly influenced habitability of huemul, where $22 \%$ occurred at lower ( $<400$ m.a.s.l.), $61 \%$ at the middle (400-1000 m.a.s.l.), and $17 \%$ at higher (>1000 m.a.s.l.) elevations. However, habitat qualities were equally distributed across the elevation gradient. These distribution found in the HSM differed with field observation points, where 9\% occurred at lower ( $<400$ m.a.s.l.), $79 \%$ at the middle (4001000 m.a.s.l.), and $12 \%$ at higher (>1000 m.a.s.l.) elevations.
HSM and natural reserve network

The analysis showed that $54.7 \%$ of the potential habitat occurred inside the protection areas network (Table 5), where all the habitat quality classes were well represented (52.2\% low, 54.5\% medium, and 57.7\% high). The National Parks protected $59.6 \%$ of these areas, where Los Glaciares National Park contained the greater suitable areas for the species $\left(1308 \mathrm{~km}^{2}\right)$ followed by the Perito Moreno National Park with $236 \mathrm{~km}^{2}$ (Table 6). The Provincial reserves represented the other $40.4 \%$ of the protected areas, where the most important sites were located at TucuTucu $\left(636 \mathrm{~km}^{2}\right)$, Magallanes peninsula $\left(188 \mathrm{~km}^{2}\right)$, and Lago del Desierto $\left(185 \mathrm{~km}^{2}\right)$. 
Table 3 Characterization (mean and standard deviation) of the climatic and topographic variables of the potential habitat suitability map of huemul classified according to their values: Total represents the values of the entire province, while unsuitable (<40\%), low (40-50\%), medium (50-70\%), and high (70-100\%) were classified according to the modeling

\begin{tabular}{|c|c|c|c|c|c|}
\hline Variable & Total & Unsuitable & Low & Medium & High \\
\hline AMT & $7.8(2.4)$ & $7.8(2.4)$ & $4.9(1.4)$ & $5.3(1.1)$ & $5.5(1.0)$ \\
\hline MAXWM & 19.6(3.2) & 19.6(3.1) & 15.2(1.6) & 15.6(1.3) & 15.7(1.1) \\
\hline MINCM & $-2.7(2.2)$ & $-2.6(2.2)$ & $-4.1(1.4)$ & $-3.7(1.3)$ & $-3.4(2.0)$ \\
\hline MTWEQ & $5.7(2.9)$ & $5.7(3.0)$ & $4.3(1.7)$ & $4.7(1.5)$ & $4.8(1.5)$ \\
\hline MTDQ & $9.8(3.7)$ & $9.9(3.7)$ & $7.2(2.5)$ & $7.7(2.2)$ & $7.7(2.0)$ \\
\hline MTWAQ & $13.2(2.8)$ & $13.3(2.8)$ & $9.5(1.5)$ & $9.9(1.2)$ & $10.1(1.0)$ \\
\hline MTCQ & $1.9(2.1)$ & $1.9(2.1)$ & $-0.1(1.4)$ & $0.4(1.1)$ & $0.6(1.1)$ \\
\hline MDR & 10.3(0.6) & $10.4(0.6)$ & $9.1(0.5)$ & $9.1(0.5)$ & $9.0(0.5)$ \\
\hline ISO & $46.4(0.2)$ & $46.6(0.2)$ & $47.1(0.1)$ & $47.1(0.1)$ & $46.8(0.1)$ \\
\hline TS & $4.5(0.4)$ & $4.5(0.4)$ & $3.7(0.2)$ & $3.7(0.2)$ & $3.7(0.2)$ \\
\hline TAR & $22.2(1.8)$ & $22.3(1.7)$ & 19.3(1.0) & 19.3(0.9) & $19.2(0.8)$ \\
\hline $\mathrm{AP}$ & $245.9(181.4)$ & $238.5(170.9)$ & 610.8(307.6) & $602.1(163.5)$ & $621.2(256.0)$ \\
\hline PWEM & $30.2(18.9)$ & 29.4(17.9) & $67.1(30.1)$ & $66.4(26.3)$ & $68.3(25.9)$ \\
\hline PDM & $13.6(12.5)$ & $13.1(11.8)$ & $38.2(21.9)$ & $37.7(18.6)$ & $39.1(17.8)$ \\
\hline PWEQ & 79.8(53.2) & $77.6(50.2)$ & 187.8(86.5) & 186.6(76.3) & 192.4(75.6) \\
\hline PDQ & $46.4(41.1)$ & $44.8(38.9)$ & $125.1(72.2)$ & $122.4(60.4)$ & $126.7(57.7)$ \\
\hline PWAQ & $53.6(42.9)$ & $52.0(40.6)$ & $134.2(76.0)$ & 132.3(63.8) & $137.5(60.7)$ \\
\hline PCQ & $67.3(46.0)$ & $65.4(43.3)$ & $160.1(76.5)$ & 158.9(67.9) & 163.7(67.3) \\
\hline PS & $24.4(6.6)$ & $24.5(6.5)$ & 18.8(6.5) & $18.5(5.4)$ & $17.8(4.5)$ \\
\hline EVTP & $807.9(101.6)$ & $810.9(100.3)$ & $656.7(42.2)$ & $663.3(35.1)$ & $663.7(29.2)$ \\
\hline GAl & $0.3(0.4)$ & $0.3(0.3)$ & $1.0(0.5)$ & $0.9(0.4)$ & $0.9(0.4)$ \\
\hline ELE & 468.8(383.8) & 464.7(384.6) & 738.4(327.4) & 664.6(299.4) & $616.9(284.4)$ \\
\hline SLO & $5.0(5.8)$ & 4.8(5.4) & $15.7(12.1)$ & $15.4(12.1)$ & $13.6(10.4)$ \\
\hline
\end{tabular}

AMT annual mean temperature $\left({ }^{\circ} \mathrm{C}\right), M D R$ mean diurnal range $\left({ }^{\circ} \mathrm{C}\right), M A X W M$ maximum temperature of warmest month $\left({ }^{\circ} \mathrm{C}\right), \mathrm{MINCM}$ minimum temperature of coldest month $\left({ }^{\circ} \mathrm{C}\right), M T W E Q$ mean temperature of wettest quarter $\left({ }^{\circ} \mathrm{C}\right), M T D Q$ mean temperature of driest quarter $\left({ }^{\circ} \mathrm{C}\right), \mathrm{MTWAQ}$ mean temperature of warmest quarter $\left({ }^{\circ} \mathrm{C}\right)$, MTCQ mean temperature of coldest quarter $\left({ }^{\circ} \mathrm{C}\right)$, ISO isothermality $(\%), T S$ temperature seasonality $\left({ }^{\circ} \mathrm{C}\right), T A R$ temperature annual range $\left({ }^{\circ} \mathrm{C}\right), A P$ mean annual precipitation $\left(\mathrm{mm}_{\mathrm{m}} \mathrm{ear}^{-1}\right)$, PWEM precipitation of wettest month $\left(\mathrm{mm}\right.$ month $\left.{ }^{-1}\right)$, PDM precipitation of driest month (mm month $\left.{ }^{-1}\right)$, PWEQ precipitation of wettest quarter (mm quarter $\left.{ }^{-1}\right), P D Q$ precipitation of driest quarter $\left(\mathrm{mm}\right.$ quarter $\left.{ }^{-1}\right), P W A Q$ precipitation of warmest quarter $\left(\mathrm{mm}\right.$ quarter $\left.{ }^{-1}\right), P C Q$ precipitation of coldest quarter $\left(\mathrm{mm}^{2}\right.$ quarter $\left.{ }^{-1}\right), P S$ precipitation seasonality (\%), EVTP global potential evapo-transpiration ( $\mathrm{mm}_{\text {year }}{ }^{-1}$ ), GAl global aridity index, ELE elevation (m.a.s.I.), SLO slope (\%)

\section{Discussion}

\section{Field observation database of huemul}

The used database presented several constrains that must be considered for the discussion of obtained results. Database of huemul is based on direct (sight of individuals) or indirect signs (antlers, bones, feces, or foot prints) (from 1997 to date) along the round year (Vila et al. 2006;

Table 4 Area of each category of the potential habitat suitability map of huemul in Santa Cruz province, classified according to their current occurrence according to field observation data base and the modeled potential distribution, where low is $40-50 \%$,

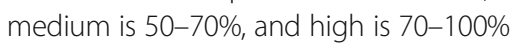

\begin{tabular}{lllll}
\hline Variable & Low & Medium & High & Total \\
\hline Model $\left(\mathrm{km}^{2}\right)$ & 1700.1 & 1540.2 & 1493.8 & 4734.1 \\
Actual $(\%)$ & 33.1 & 38.6 & 46.5 & 39.1 \\
Potential (\%) & 66.8 & 61.4 & 53.4 & 60.8 \\
\hline
\end{tabular}

Quevedo et al. 2017). Therefore, the current database is limited due to:(i) database did not include the historical distribution of the species (e.g., archeological findings, museum collections, or oral tradition of local people before 1997), (ii) huemul records were directly related with field accessibility (e.g., remote areas was underrepresented), (iii) data were collected or checked by specialists of some institutions (e.g., Administración de Parques Nacionales, Argentina) and few participation of local inhabitants (mostly ranch workers) focused mainly inside natural reserves, and (iv) lack of exact date of observation, so it was not possible to consider seasonal or yearly influences (Newbold 2010; Díaz et al. 2013; Briceño et al. 2013). Our study area included all the Santa Cruz province records beyond the current distribution of huemul, and we decided to include all the province information due to the historical distribution of huemul reported for the species across all the province: (i) direct sights of huemul were reported by 


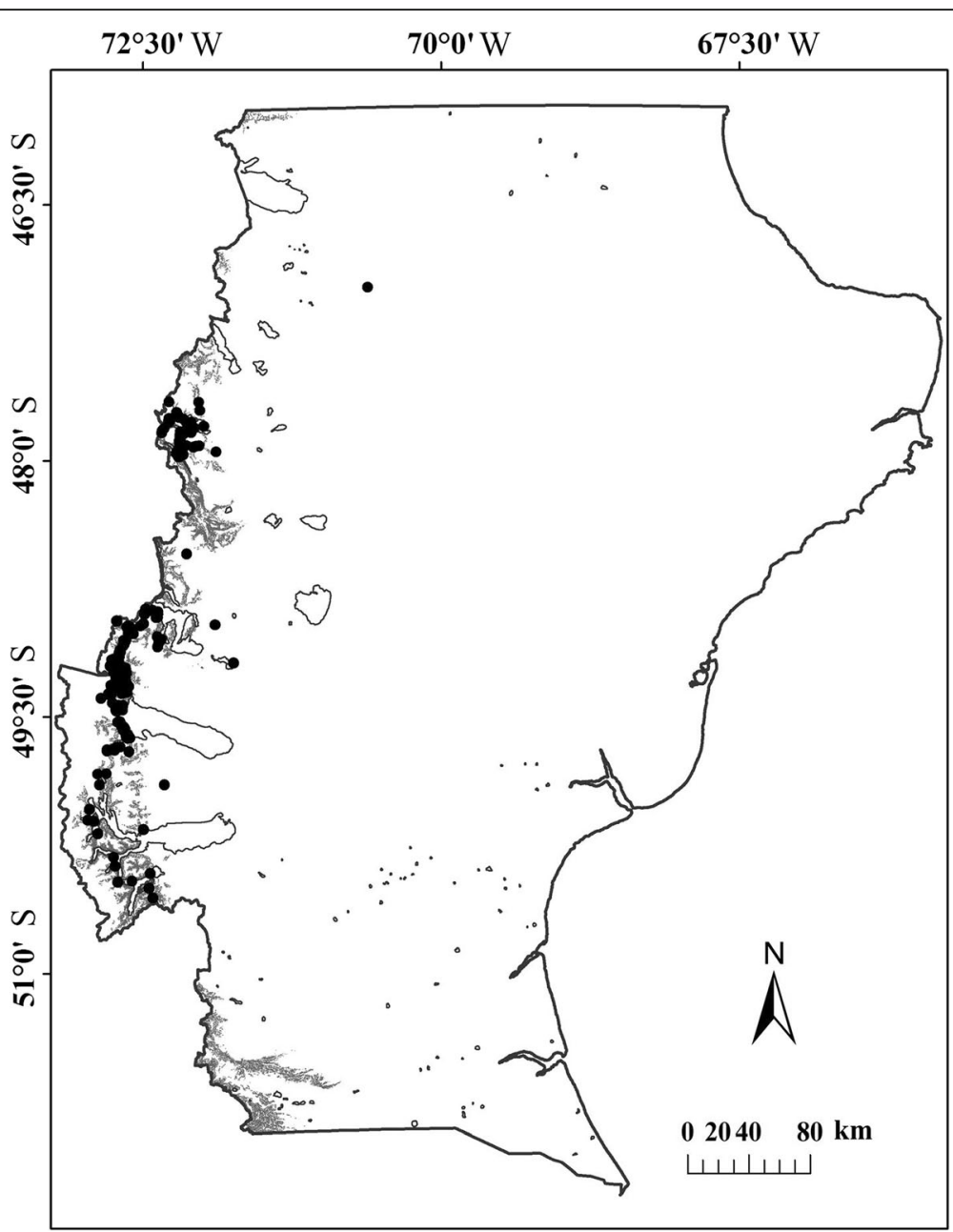

Fig. 4 Comparison between field data (black dots) and habitat suitability (pale gray, 40-100\%) of huemul in Santa Cruz province

the first Spanish expeditionary along the ocean shores from Puerto Deseado ( $\left.47^{\circ} 45^{\prime} 21^{\prime \prime} \mathrm{SL}, 65^{\circ} 53^{\prime} 38^{\prime \prime} \mathrm{WL}\right)$ to Magellan strait (Díaz and Smith-Flueck 2000), (ii) archeological findings across Santa Cruz steppe, e.g., Los Toldos ( $47^{\circ} 22^{\prime} 00^{\prime \prime} \mathrm{S}$ and $\left.68^{\circ} 58^{\prime} 00^{\prime \prime} \mathrm{W}\right)$ ), Punta Entrada (50 08' $00^{\prime \prime} \mathrm{SL}$ and $\left.68^{\circ} 22^{\prime} 00^{\prime \prime} \mathrm{WL}\right)$, and Laguna Cóndor (51 $45^{\prime}$ $41^{\prime \prime} \mathrm{S}$ and $71^{\circ} 38^{\prime} 24^{\prime \prime} \mathrm{W}$ ) (Cruz et al. 2010; Fernández et al. 2015); (iii) Stag River ranch located at southern Santa

Table 5 Areas of the potential habitat suitability map of huemul in Santa Cruz province (Table 4) classified according their protection status: Provincial natural reserves (PR) and National Parks (NP) and unprotected, where low is $40-50 \%$, medium is $50-70 \%$, and high is $70-100 \%$

\begin{tabular}{llllll}
\hline Variable & & Low & Medium & High & Total \\
\hline Protected & PR (\%) & 42.0 & 41.6 & 37.6 & 40.4 \\
& NP (\%) & 58.0 & 58.4 & 62.4 & 59.6 \\
& Total (\%) & 52.2 & 54.5 & 57.7 & 54.7 \\
\multicolumn{2}{l}{ Unprotected (\%) } & 47.8 & 45.5 & 42.3 & 45.3 \\
\hline
\end{tabular}

Cruz were named due to the presence of huemul (sights reported from its foundation in 1894 until middle twentieth century). Database showed an equal distribution of observation points between forests and open lands, although huemul is considered as a forest species (Corti et al. 2011; Quevedo et al. 2017). However, several authors mentioned the use of grasslands and shrublands, indicating a preference by huemul for the ecotone areas between forests and open lands (Vila et al. 2006, 2010; Díaz et al. 2013; Briceño et al. 2013). This was also supported by several studies that found greater huemul archeological rests in these ecotone areas (Fernández et al. 2015; L'Heureux 2016).The forest observation points were mostly found in $N$. pumilio woods, with a high preference for this environment compared to other Nothofagus species. Díaz et al. (2013) also indicated higher preference of huemul for $N$. pumilio (especially during autumn and winter) than N. antarctica forests. However, it is possible that $N$. antarctica forest type was under represented in the used database due to trade-offs with ranching during the last decades (Briceño 
Table 6 Areas $\left(\mathrm{km}^{2}\right)$ of potential habitat suitability map of huemul classified according to their occurrence inside each Provincial natural reserves (PR) and National Parks (NP), where low is $40-50 \%$, medium is $50-70 \%$, and high is $70-100 \%$

\begin{tabular}{lllll}
\hline Name & Low & Medium & High & Total \\
\hline Tucu Tucu (PR) & 253.1 & 218.4 & 164.2 & 635.6 \\
La Florida (PR) & 0.2 & 0.3 & 0.3 & 0.8 \\
Punta Gruesa (PR) & 5.5 & 3.3 & 2.9 & 11.8 \\
San Lorenzo (PR) & 10.9 & 7.8 & 6.5 & 25.2 \\
Lago del Desierto (PR) & 49.5 & 53.3 & 82.0 & 184.8 \\
Península de Magallanes (PR) & 53.7 & 65.6 & 68.2 & 187.5 \\
Perito Moreno (NP) & 63.5 & 71.7 & 100.4 & 235.5 \\
Los Glaciares (NP) & 451.6 & 418.4 & 438.1 & 1308.1 \\
Total & 887.9 & 838.9 & 862.6 & 2589.4 \\
\hline
\end{tabular}

et al. 2013). Finally, database showed a differential use of huemul according to the vegetation type and elevation, showing a greater preference for the forests at middle elevations and for open lands at higher elevations. This was supported by some authors (Gill et al. 2008; Díaz et al. 2013) indicating a differential use related to seasons and altitudinal gradients, e.g., alpine vegetation was preferred in summer while forests and shrublands were used during autumn and winter following the phenological development of the different vegetation types along the growing season. Beside this, huemul showed a preference for mid-elevations and steep slopes. Other authors reported the use of low elevations and gentle slopes (Povilitis 1998; Díaz and Smith-Flueck 2000), while other studies remarked the preference of the species for steep, rocky, north-facing aspect with irregular topography (Gill et al. 2008).

\section{HSM and environmental characteristics}

Habitat quality assessment and HSM can assist in designing management plans at regional level to expand protected areas or to create new ones in order to protect certain species or habitats of particular importance in managed forest improving regional planning (Lachat and Bütler 2009). This also can help to locate suitable sites for reintroduction programs or to design fauna corridors, favoring the success of regional conservation planning (Klar et al. 2008; Zheng et al. 2016; Quevedo et al. 2017). Identifying the key environmental variables that determine the niche is one of the most crucial HSM operations (Hirzel and Le Lay 2008). Organisms usually respond to a complexity of interdependent factors including many environmental variables (Rydgren et al. 2003), e.g., Grinnell (1917) listed the factors that potentially affect the species distribution as vegetation, food, climate, soil, breeding and refuge sites, inter-specific effects, and species preferences. However, it is very difficult to find this type of information in remote areas such as Southern Patagonia (Martínez Pastur et al. 2016). Remote sensing and GIS technologies provide a wide spectrum of coarse spatial information that can assist in the evaluation of macro-distribution of species (e.g., climate, topography, and landscape) (Estrada-Peña and Venzal 2007; Hirzel and Le Lay 2008). The employment of climate (e.g., temperature or rainfall), topographic (e.g., slope or aspect), and landscape (e.g., forest edge density) were widely used for habitat modeling in the literature (Elith and Leathwick 2009; Martínez Pastur et al. 2016), as it has been used here for modeling HSM for huemul in Southern Patagonia. Also, the distribution of huemul in Northern Patagonia was estimated using similar predictable variables (Quevedo et al. 2017) including a large potential distribution area where the species is not present there since 1980. Other studies also remark the importance of elevation and aspect for huemul (Gill et al. 2008; Díaz et al. 2013), including forested and open land environments (Vila et al. 2006, 2010; Briceño et al. 2013).

Presence-only methods using ENFA (Hirzel et al. 2002) were largely used for several studies around the World (e.g., Allouche et al. 2008; Lachat and Bütler, 2009; Bajocco et al. 2016) and Patagonia (Martínez Pastur et al. 2016). ENFA calculates habitat suitability based on an analysis of marginality (how the species' mean of each location differs from the mean of all sites of the study area) and environmental tolerance (how the species' variance of each location differs with the global variance of all sites) (Allouche et al. 2008). This methodology is suitable for areas with low data availability such as Southern Patagonia, where databases for rare or endangered species very often consist in a set of observed occurrences (presence-only data) being useful for studies that analyze the ecological niche based only in the data of their presence (Guisan and Zimmermann 2000; Soberón and Peterson 2005).The developed HSM allowed us to determine areas with different habitat quality closely related to mountain environments and ecotone areas. The applied modeling identifies habitat areas in different ecosystem types, including alpine grasslands, the three existing forest types, and the ecotone areas with the steppe (grasslands and shrublands), in coincidence with the hypothesis of their historical distribution (Díaz 1993; Flueck and Smith-Flueck 2012; Fernández et al. 2015). The developed HSM showed a greater potential area distribution than those derived from the field data observations. Current populations of huemul were concentrated around big lakes in the central area in natural reserves (e.g., Perito Moreno and Los Glaciares National Parks) (see Fig. 3b-d). Vila et al. (2010) also indicated these areas as the best habitat for huemul in the pristine areas of Los Glaciares National Park and a density of 1.2 ind $\mathrm{km}^{-2}$ in the Perito Moreno National Park. Beside this, the modeling also identified two potential areas in the northern territory of the province (see Fig. 3a, b), with lower habitat quality and with no recent field data observations. However, archeological evidence was found along the steppe and ecotone areas (Charlin et al. 2011; Fernández et al. 
2015). Close sights in Chilean territory (Corti et al. 2011; Barberena et al. 2011; Elbroch and Wittmer 2013) support the idea that the species could occur there in the past. Also, our modeling approach identified greater areas in the southern Santa Cruz province near the forests close to Rio Turbio (see Fig. 3e) without recent field data observations. Once again, archeological evidence (Fernández et al. 2015; L'Heureux 2016) and close sights in Chilean territory (Smith-Flueck et al. 2011; Garay et al. 2016), as well as oral tradition of some ranchers (e.g., Stag River ranch), support the idea that the species occurred there in the past. In this sense, the decline of huemul can be due to different human related factors (López-Alfaro et al. 2012; Corti et al. 2013; Briceño et al. 2013) which greatly impacted the marginal huemul populations (north and southern distribution areas in the province) in those ecosystems with greater ranching activities (e.g., steppe and $N$. antarctica forests under silvopastoral uses). Regarding to climate, huemul occupies a narrow environmental conditions associated to the mountain regions. High habitat quality was related to lower temperature rather than the mean temperature of the province, and higher rainfall was preferred as cited for other authors (Frid 1994, 1999; Povilitis 1998). Other authors cited for northern Patagonia that less amplitude in climate variables derived in higher quality habitats (Quevedo et al. 2017).

\section{HSM and natural reserve networks}

Huemul is an endangered species (Black-Decima et al. 2016), estimating 350-500 individuals in 50 fragmented subpopulations for all Patagonia Argentina (Díaz and Smith-Flueck 2000). For this reason, the species receives the greatest legal protection in Argentina represented by a declaration as national natural monument (Law 24,702/96) and included into the national conservation and recovery plan since 2001. However, regardless of the increasing conservation efforts, the recovery of huemul was not improved in recent years, and in fact, many subpopulations continued to be disappearing, even within the National Parks (Povilitis 1983, 1998; Frid 2001; Flueck and Smith-Flueck 2006, 2011). Nearly half of habitat suitability areas for huemul are inside the National Parks and Provincial natural reserves according to our HSM, where most of the remained groups survive in these areas according to our field observation database (e.g., see Figs. 1d and 4). Other studies indicated that protection of the habitat of huemul was similar to our modeling results. Vila et al. (2006) estimated that $47 \%$ of the habitat area is inside natural reserves of Chile and Argentina, and Quevedo et al. (2017) determined 40\% for northern Patagonia. In this sense, the conservation strategy of land-sparing (Todd et al. 2016; Coetzee 2017) was useful to conserve the species to date because the retraction of the potential habitat areas were found in ranches with high intensity economic activities (e.g., sheep and cattle breeding, as well as forestry practices) and other human-related impacts (e.g., poaching).
However, also, there are large off-reserve areas with high quality habitat, mainly in private ranches that may act as another refuges and connectivity among the current natural reserve network (Corti et al. 2011). In this sense, the conservation strategy of land-sharing must be improved (Gustafsson et al. 2012; Martínez Pastur et al. 2016, 2017) to avoid the increasing fragmentation of the current populations and to increase the habitat quality availability for huemul off-reserves. Several private initiatives support this strategy by modifying the economic activities inside the ranches such as the reduction of cattle stocking rate and increasing other activities such as rural tourism (e.g., Ea. Río Condor at $49^{\circ} 05^{\prime} 04^{\prime \prime} \mathrm{S}$ and $72^{\circ} 33^{\prime} 07^{\prime \prime} \mathrm{W}$, and Ea. Los Huemules at $49^{\circ} 13^{\prime} 04^{\prime \prime} \mathrm{S}$ and $\left.72^{\circ} 57^{\prime} 37^{\prime \prime} \mathrm{W}\right)$. It is necessary to implement new provincial conservation efforts to promote innovative management strategies in ranches with high habitats value to increase the huemul protection (Smith-Flueck et al. 2011) by maintaining the productive incomes (e.g., local reserves, corridors, and fences to avoid the contact between domestic species and huemul populations) (Gilbert-Norton et al. 2010; Corti et al. 2011). Intensive economic management can be designed to preserve target species (e.g., define a lower canopy cover to promote higher understory development) at stand or landscape level (e.g., increasing the habitat heterogeneity among management units) (Gustafsson et al. 2012; Carpentier et al. 2017). For example, in northern Patagonia, fragmentation and habitat loss were the main drivers for population declination (Black-Decima et al. 2016); however, intensively managed areas such as forest plantations can be used for huemul with the appropriate planning (Sandvig et al. 2016).

\section{Conclusions}

We can define the potential habitat of huemul, where forest edges and ecotone zones (e.g., mainly alpine environments) were the most important used environments, as well as some forest types (e.g., N. pumilio vs. other Nothofagus species). Habitat losses were found in the extreme potential distribution areas modeled in our study (northern and southern areas), which can be related to ranch activities and other human impacts. The current reserve networks maintain half of the potential habitat of the huemul in Santa Cruz, where National Parks presented the same importance as the Provincial natural reserves. Habitat suitability model for huemul can be used as a decision support system for new management strategies at different landscape levels to improve the current conservation efforts. The obtained results also can contribute in future research to (i) determine the ecological requirements of the species and its limiting factors, (ii) define new reserves, (iii) develop strategies to improve and maintain the connectivity among reserves, (iv) develop off-reserves strategies with ranch owners, and (v) predict potential climate change effects in the long term. 


\section{Appendix 1}

Table 7 Explanatory variables used in modeling potential habitat suitability of huemul

\begin{tabular}{|c|c|c|c|c|}
\hline Category & Description & Code & Unit & Data source \\
\hline \multirow[t]{21}{*}{ Climate } & Mean annual temperature & AMT & ${ }^{\circ} \mathrm{C}$ & WorldClim ${ }^{a}$ \\
\hline & Mean diurnal range & MDR & ${ }^{\circ} \mathrm{C}$ & WorldClima \\
\hline & Isothermality & 150 & $\%$ & WorldClim ${ }^{a}$ \\
\hline & Temperature seasonality & TS & ${ }^{\circ} \mathrm{C}$ & WorldClim $^{\mathrm{a}}$ \\
\hline & Max temperature of warmest month & MAXWM & ${ }^{\circ} \mathrm{C}$ & WorldClima \\
\hline & Min temperature of coldest month & MINCM & ${ }^{\circ} \mathrm{C}$ & WorldClim ${ }^{a}$ \\
\hline & Temperature annual range & TAR & ${ }^{\circ} \mathrm{C}$ & WorldClima \\
\hline & Mean temperature of wettest quarter & MTWEQ & ${ }^{\circ} \mathrm{C}$ & WorldClim ${ }^{a}$ \\
\hline & Mean temperature of driest quarter & MTDQ & ${ }^{\circ} \mathrm{C}$ & WorldClima \\
\hline & Mean temperature of warmest quarter & MTWAQ & ${ }^{\circ} \mathrm{C}$ & WorldClim ${ }^{a}$ \\
\hline & Mean temperature of coldest quarter & MTCQ & ${ }^{\circ} \mathrm{C}$ & WorldClima \\
\hline & Mean annual precipitation & AP & $m m$ year $^{-1}$ & WorldClim ${ }^{a}$ \\
\hline & Precipitation of wettest month & PWEM & $\mathrm{mm}$ month ${ }^{-1}$ & WorldClima \\
\hline & Precipitation of driest month & PDM & $\mathrm{mm}$ month ${ }^{-1}$ & WorldClima \\
\hline & Precipitation seasonality & PS & $\%$ & WorldClim ${ }^{a}$ \\
\hline & Precipitation of wettest quarter & PWEQ & $\mathrm{mm}$ quarter ${ }^{-1}$ & WorldClima \\
\hline & Precipitation of driest quarter & PDQ & $m m$ quarter $^{-1}$ & WorldClim ${ }^{a}$ \\
\hline & Precipitation of warmest quarter & PWAQ & $\mathrm{mm}$ quarter ${ }^{-1}$ & WorldClima \\
\hline & Precipitation of coldest quarter & PCQ & $\mathrm{mm}$ quarter $^{-1}$ & WorldClim ${ }^{a}$ \\
\hline & Global potential evapo-transpiration & EVTP & $m m$ year $^{-1}$ & $\mathrm{CSI}^{\mathrm{b}}$ \\
\hline & Global aridity index & GAl & & $\mathrm{CSI}^{\mathrm{b}}$ \\
\hline \multirow[t]{8}{*}{ Topography } & Elevation & ELE & m.a.s.l. & $\mathrm{DEM}^{\mathrm{c}}$ \\
\hline & Slope & SLO & $\%$ & $\mathrm{DEM}^{\mathrm{c}}$ \\
\hline & Aspect & ASP & Cosine & $\mathrm{DEM}^{\mathrm{c}}$ \\
\hline & Aspect & ASP & Sine & $\mathrm{DEM}^{\mathrm{c}}$ \\
\hline & Distance to locality & $\mathrm{DL}$ & km & SIT Santa Cruz ${ }^{d}$ \\
\hline & Distance to lakes & DWD & km & SIT Santa Cruz ${ }^{d}$ \\
\hline & Distance to rivers & DR & km & SIT Santa Cruz ${ }^{d}$ \\
\hline & Distance to routs & DW & km & SIT Santa Cruz ${ }^{d}$ \\
\hline \multirow[t]{11}{*}{ Landscape } & Forest edge density & ED & $\mathrm{m} \mathrm{ha}{ }^{-1}$ & Forest map/Fragstats ${ }^{\mathrm{e}}$ \\
\hline & Total core area & TCA & ha & Forest map/Fragstats ${ }^{e}$ \\
\hline & Large parch index & LPI & $\%$ & Forest map/Fragstats ${ }^{\mathrm{e}}$ \\
\hline & Normalized difference vegetation index & NDVI & & MODIS $^{\dagger}$ \\
\hline & Net primary productivity & NPP & $\operatorname{gr~C~m}^{-2}$ year $^{-1}$ & MODIS \\
\hline & Desertification & DES & Degree & CENPAT ${ }^{h}$ \\
\hline & Total forest & TF & Occurrence & Forest map ${ }^{d}$ \\
\hline & Total mixed forests & TMF & Occurrence & Forest map ${ }^{d}$ \\
\hline & Total N. pumilio & TNP & Occurrence & Forest map ${ }^{d}$ \\
\hline & Total N. antarctica & TNA & Occurrence & Forest map ${ }^{d}$ \\
\hline & Total Nothofagus betuloides & TNB & Occurrence & Forest map ${ }^{d}$ \\
\hline
\end{tabular}

a Hijmans et al. (2005)

${ }^{\mathrm{b}}$ Consortium for Spatial Information (CSI) (Zomer et al. 2008)

'Farr et al. (2007)

${ }^{\mathrm{d} S \mathrm{IT}}$ - Santa Cruz (http://spm.sitsantacruz.gob.ar/)

'McGarigal et al. (2012)

ORNL DAAC (2008)

'Zhao and Running (2010)

hel Valle et al. (1998) 


\section{Acknowledgements}

We also want to thanks to Administración de Parques Nacionales for the access of their databases. This research is part of the doctoral thesis of YMR (Faculty of Ciencias Agrarias y Forestales in the Universidad Nacional de la Plata).

\section{Funding}

This research was supported by the financial support of the "Operationalisation of Ecosystem Services and Natural Capital: From concepts to real-world applications (OpenNESS)" project financed under the European Commission's Seventh Framework Programme (project number 308428).

\section{Authors' contributions}

YMR and AHH managed and designed the GIS project. HP helped with the data base and support with the data analyses into the National Reserve network. PLP and GMP designed the data analyses. All the authors actively participate in the discussion and writing of the manuscript. All authors read and approved the final manuscript.

\section{Competing interests}

The authors declare that they have no competing interests.

\section{Publisher's Note}

Springer Nature remains neutral with regard to jurisdictional claims in published maps and institutional affiliations.

\section{Author details}

'Laboratorio de Recursos Agroforestales, Centro Austral de Investigaciones Científicas (CONICET), Houssay 200, Ushuaia 9410, Tierra del Fuego, Argentina. ${ }^{2}$ UNPA-INTA-CONICET. CC 332, Río Gallegos 9400, Santa Cruz, Argentina. ${ }^{3}$ Delegación Regional Patagonia Norte, Administración de Parques Nacionales, Vicealmirante O'Connor 1188, San Carlos de Bariloche 8400, Río Negro, Argentina.

\section{Received: 23 May 2017 Accepted: 4 July 2017}

Published online: 17 August 2017

\section{References}

Acevedo P, Ward Al, Real R, Smith GC (2010) Assessing biogeographical relationships of ecologically related species using favourability functions: a case study on British deer. Diver Distr 16:515-528

Allouche O, Steinitz O, Rotem D, Rosenfeld A, Kadmon R (2008) Incorporating distance constraints into species distribution models. J Appl Ecol 45:599-609

Bajocco S, Ceccarelli T, Smiraglia D, Salvati L, Ricotta C (2016) Modeling the ecological niche of long-term land use changes: the role of biophysical factors. Ecol Indic 60:231-236

Barberena R, Méndez C, Mena F, Reyes O (2011) Endangered species, archaeology, and stable isotopes: huemul (Hippocamelus bisulcus) isotopic ecology in CentralWestern Patagonia (South America). J Archaeol Sci 38:2313-2323

Barr LM, Watson JEM, Possingham HP, Iwamura T, Fuller RA (2016) Progress in improving the protection of species and habitats in Australia. Biol Conserv 200:184-191

Black-Decima PA, Corti P, Díaz N, Fernandez R, Geist V, Gill R, Gizejewski Z, Jiménez J, Pastore H, Saucedo C, Wittmer H (2016) Hippocamelus bisulcus. The International Union for Conservation of Nature (IUCN) red list of threatened species: e.T10054A22158895.

Boyce MS, Vernier PR, Nielsen SE, Schmiegelow F (2002) Evaluating resource selection functions. Ecol Model 157:281-300

Braunisch V, Bollmann K, Graf RF, Hirzel A (2008) Living on the edge--modelling habitat suitability for species at the edge of their fundamental niche. Ecol Model 214:153-167

Briceño C, Knapp LA, Silva A, Paredes J, Avendaño I, Vargas A, Sotomayor J, Vila AR (2013) Detecting an increase in an endangered huemul Hippocamelus bisulcus population following removal of cattle and cessation of poaching in coastal Patagonia, Chile. Oryx 47:273-279

Carpentier S, Filotas E, Handa IT, Messier C (2017) Trade-offs between timber production, carbon stocking and habitat quality when managing woodlots for multiple ecosystem services. Environ Conserv 44:14-23

Charlin J, Borrero L, Pallo MC (2011) Ocupaciones humanas en el área noroccidental del río Gallegos (Prov. Santa Cruz, Argentina). In: Borrero LA, Borrazzo K (eds)
Bosques, montañas y cazadores: Investigaciones arqueológicas en Patagonia meridional. IMHICIHU, Buenos Aires, Argentina, pp 179-210

Coetzee BWT (2017) Evaluating the ecological performance of protected areas. Biodiv Conserv 26:231-236

Corti P, Shafer ABA, Coltman DW, Festa-Bianchet M (2011) Past bottlenecks and current population fragmentation of endangered huemul deer (Hippocamelus bisulcus): implications for preservation of genetic diversity. Conserv Genet 12:119-128

Corti P, Saucedo C, Herrera P (2013) Evidence of bovine viral diarrhea, but absence of infectious bovine rhinotracheitis and bovine brucellosis in the endangered huemul deer (Hippocamelus bisulcus) in Chilean Patagonia. J Wildl Dis 49:744-746

Cruz I, Muñoz AS, Caracotche MS (2010) Un artefacto en asta de huemul (Hippocamelus bisulcus) en depósitos arqueológicos de la Costa Atlántica: implicaciones para la movilidad humana y la distribución de la especie. Magallania 38:287-294

Del Valle HF, Elissalde NO, Gagliardini DA, Milovich J (1998) Status of desertification in the Patagonian region: assessment and mapping from satellite imagery. Arid Land Res Manage 12:95-121

Díaz NI (1993) Changes in the range distribution of Hippocamelus bisulcus in Patagonia. Z Saugetierkd 58:344-351

Díaz NI, Smith-Flueck JM (2000) The Patagonian huemul: a mysterious deer on the brink of extinction. LOLA, Buenos Aires, Argentina

Díaz P, Marqués BI, Vila AR (2013) Seasonal habitat use and selection of the endangered huemul deer (Hippocamelus bisulcus) in Patagonian Andes. Mammalia 77:371-380

Elbroch LM, Wittmer HU (2013) The effects of puma prey selection and specialization on less abundant prey in Patagonia. J Mammal 94:259-268

Elith J, Leathwick JR (2009) Species distribution models: ecological explanation and prediction across space and time. Annu Rev Ecol Evol Syst 40:677-697

ESRI (2011) ArcGIS desktop: release 10. Environmental Systems Research Institute Inc, Redlands, USA.

Estrada-Peña A, Venzal JM (2007) Climate niches of tick species in the Mediterranean region: modeling of occurrence data, distributional constraints, and impact of climate change. J Med Entomol 44:1130-1138

Farr TG, Rosen PA, Caro E, Crippen R, Duren R, Hensley S, Kobrick M, Paller M Rodriguez E, Roth L, Seal D, Shaffer S, Shimada J, Umland J, Werner M, Oskin M, Burbank D, Alsdorf D (2007) The shuttle radar topography mission. Rev Geophys 45:RG2004

Fernández PM, Cruz I, Belardi JB, De Nigris M, Muñoz AS (2015) Human predation and natural history of huemul (Cervidae; Hippocamelus bisulcus Molina) in Patagonia: a zooarchaeological analysis. J Ethnobiol 35:472-498

Flueck WT, Smith-Flueck JM (2006) Predicaments of endangered huemul deer, Hippocamelus bisulcus, in Argentina: a review. Eur J Wildl Res 52:69-80

Flueck WT, Smith-Flueck JM (2011) Recent advances in the nutritional ecology of the Patagonian huemul: implications for recovery. Anim Prod Sci 51:311-326

Flueck WT, Smith-Flueck JM (2012) Huemul heresies: beliefs in search of supporting data. 1. Historical and zooarcheological considerations. Anim Prod Sci 52:685-693

Frid A (1994) Observations on habitat use and social organization of a huemul Hippocamelus bisulcus coastal population in Chile. Biol Conserv 67:13-19

Frid A (1999) Huemul (Hippocamelus bisulcus) sociality at a periglacial site: sexual aggregation and habitat effects on group size. Can J Zoolog 77:1083-1091

Frid A (2001) Habitat use by endangered huemul (Hippocamelus bisulcus): cattle, snow, and the problem of multiple causes. Biol Conserv 100:261-267

Garay G, Ortega IM, Guineo O (2016) Social ecology of the huemul at Torres del Paine National Park, Chile. An Inst Patagonia 44:25-38

Gilbert-Norton L, Wilson R, Stevens JR, Beard KH (2010) A meta-analytic review of corridor effectiveness. Conserv Biol 24:660-668

Gill R, Saucedo Galvez C, Aldridge D, Morgan G (2008) Ranging behaviour of huemul in relation to habitat and landscape. J Zool 274:254-260

Grinnell J (1917) Field tests of theories concerning distributional control. Am Nat $51: 115-128$

Guisan A, Zimmermann NE (2000) Predictive habitat distribution models in ecology. Ecol Model 135:147-186

Gustafsson L, Baker SC, Bauhus J, Beese WJ, Brodie A, Kouki J, Lindenmayer DB, Löhmus A, Martínez Pastur G, Messier C, Neyland M, Palik B, SverdrupThygeson A, Volney WJA, Wayne A, Franklin JF (2012) Retention forestry to maintain multifunctional forests: a world perspective. BioScience 62:633-645

Hiimans RJ, Cameron SE, Parra JL, Jones PG, Jarvis A (2005) Very high resolution interpolated climate surfaces for global land areas. Int J Climat 25:1965-1978 
Hirzel AH, Arlettaz R (2003) Modelling habitat suitability for complex species distributions by the environmental-distance geometric mean. Environ Manage 32:614-623

Hirzel AH, Le Lay G (2008) Habitat suitability modelling and niche theory. J Appl Ecol 45:1372-1381

Hirzel AH, Helfer V, Metral F (2001) Assessing habitat-suitability models with a virtual species. Ecol Model 145:111-121

Hirzel AH, Hausser J, Chessel D, Perrin N (2002) Ecological-niche factor analysis: how to compute habitat-suitability maps without absence data? Ecology 83: 2027-2036

Hirzel AH, Hausser J, Perrin N (2004) Biomapper 3.1. Division of conservation biology, University of Bern, Bern, Switzerland

Hirzel AH, Le Lay G, Helfer V, Randin C, Guisan A (2006) Evaluating habitat suitability models with presence-only data. Ecol Model 199:142-152

Jenness J (2007) Some thoughts on analyzing topographic habitat characteristics. Ed Jenness Enterprises, Flagstaff, USA

Jiménez-Valverde A, Gómez JF, Lobo J, Baselga A, Hortal J (2008) Challenging species distribution models: the case of Maculinea nausithous in the Iberian Peninsula. Ann Zool Fennici 45:200-210

Klar N, Fernández N, Kramer-Schadt S, Herrmann M, Trinzen M, Büttner I, Niemitz C (2008) Habitat selection models for European wildcat conservation. Biol Conserv 141:308-19

L'Heureux GL (2016) El uso de la fauna en laguna Cóndor, provincia de Santa Cruz, Argentina. Magallania 44:249-257

Lachat T, Bütler R (2009) Identifying conservation and restoration priorities for saproxylic and old-growth forest species: a case study in Switzerland. Environ Manage 44:105-118

López-Alfaro C, Estades CF, Aldridge DK, Gill RM (2012) Individual-based modeling as a decision tool for the conservation of the endangered huemul deer (Hippocamelus bisulcus) in southern Chile. Ecol Model 244:104-116

Luque S, Martínez Pastur G, Echeverría C, Pacha MJ (2011) Overview of biodiversity loss in South America: a landscape perspective for sustainable forest management and conservation in temperate forests. In: Li C, Lafortezza R, Chen J (eds) Landscape ecology in forest management and conservation: challenges and solutions for global change. Springer, BerlinHeidelberg, Germany, pp 357-384

Martínez Pastur G, Peri PL, Soler R, Schindler S, Lencinas MV (2016) Biodiversity potential of Nothofagus forests in Tierra del Fuego (Argentina): tool proposal for regional conservation planning. Biodiv Conserv 25:1843-1862

Martínez Pastur G, Peri PL, Huertas Herrera A, Schindler S, Díaz-Delgado R, Lencinas MV, Soler R (2017) Linking potential biodiversity and three ecosystem services in silvopastoral managed forest landscapes of Tierra del Fuego, Argentina. IJBESM 13:1-11

McGarigal K, Cushman SA, Ene E (2012) FRAGSTATS v4: spatial pattern analysis program for categorical and continuous maps. University of Massachusetts, Amherst, US

Mikoláš M, Tejkal M, Kuemmerle T, Griffiths P, Svoboda M, Hlásny T, Leitão PJ, Morrissey RC (2017) Forest management impacts on capercaillie (Tetrao urogallus) habitat distribution and connectivity in the Carpathians. Land Ecol 32:163-179

Moreau G, Fortin D, Couturier S, Duchesne T (2012) Multi-level functional responses for wildlife conservation: the case of threatened caribou in managed boreal forests. J Appl Ecol 49:611-620

Newbold T (2010) Applications and limitations of museum data for conservation and ecology, with particular attention to species distribution models. Prog Phys Geog 34:3-22

Oliva G, Gonzalez L, Ruial P (2004) Áreas Ecológicas. In: González L (ed) Guía Geográfica Interactiva de Santa Cruz. INTA, Buenos Aires, Argentina, pp 14-15

ORNL DAAC (2008) MODIS Collection 5 Land Products Global Subsetting and Visualization Tool. ORNL DAAC, Oak Ridge, Tennessee, USA

Peterson AT (2006) Uses and requirements of ecological niche models and related distributional models. Biodiv Infor 3:59-72

Poirazidis K, Schindler S, Kati V, Martinis A, Kalivas D, Kasimiadis D, Wrbka T, Papageorgiou AC (2011) Conservation of biodiversity in managed forests: developing an adaptive decision support system. In: Li C, Lafortezza R, Chen J (eds) Landscape ecology and forest management: challenges and solutions in a changing globe. Springer, New York, US, pp 380-399

Povilitis A (1983) The huemul in Chile: national symbol in jeopardy? Oryx 17(1): $34-40$

Povilitis A (1998) Characteristics and conservation of a fragmented population of huemul (Hippocamelus bisulcus) in central Chile. Biodiv Conserv 86:97-104
Quevedo P, Von Hardenberg A, Pastore H, Álvarez J, Corti P (2017) Predicting the potential distribution of the endangered huemul deer Hippocamelus bisulcus in North Patagonia. Oryx 51:315-323

Rydgren $\mathrm{K}, \varnothing \mathrm{kland} \mathrm{RH}, \varnothing \mathrm{kland} \mathrm{T}$ (2003) Species response curves along environmental gradients: a case study from SE Norwegian swamp forests. J Veg Sci 14:869-880

Sandvig EM, Espinaze M, Marín-Vial P, Corti P (2016) Assessing productive lands as viable habitat for huemul in Patagonia. J Wildl Manage 80:573-578

Saucedo C, Gill R, Montero E, Aldridge D, Bustos P (2004) Huemul (Hippocamelus bisulcus) ecology research: conservation planning in Chilean Patagonia. Deer Specialist Group Newsletter 19:13-15

Smith-Flueck JM, Barri J, Ferreyra N, Nuñez A, Tomas N, Guzman J, Jimenez J (2011) Advances in ecology and conservation of Hippocamelus species in South America. Anim Prod Sci 51:378-383

Soberón J (2007) Grinnellian and eltonian niches and geographic distributions of species. Ecol Let 10:1115-1123

Soberón J, Peterson AT (2005) Interpretation of models of fundamental ecological niches and species' distribution areas. Biodiv Inf 2:1-10

Tan CKW, Rocha DG, Clements GR, Brenes-Mora E, Hedges L, Kawanishi K, Mohamad SW, Mark Rayan D, Bolongon G, Moore J, Wadey J, Campos-Arceiz A, Macdonald DW (2016) Habitat use and predicted range for the mainland clouded leopard Neofelis nebulosa in Peninsular Malaysia. Biol Conserv 206:65-74

Thorn JS, Nijman V, Smith D, Nekaris KAI (2009) Ecological niche modelling as a technique for assessing threats and setting conservation priorities for Asian slow lorises (primates: Nycticebus). Diver Distrib 15:289-98

Todd C, Lindenmayer DB, Stamation K, Acevedo-Cattaneo S, Smith S, Lumsden LF (2016) Assessing reserve effectiveness: application to a threatened species in a dynamic fire prone forest landscape. Ecol Model 338:90-100

Vidal F, Smith-Flueck JAM, FlueckWT AE (2011) Patagonian huemul deer (Hippocamelus bisulcus) under captive conditions: an historical overview. Anim Prod Sci 51:340-350

Vila AR, López R, Pastore H, Faúndez R, Serret A (2006) Current distribution and conservation of the huemul (Hippocamelus bisulcus) in Argentina and Chile. Mastozool Neotrop 13:263-269

Vila AR, Saucedo C, Aldridge D, Ramilo E, Corti P (2010) South andean huemul Hippocamelus bisulcus (Molina 1782). In: Duarte JM, González S (eds) Neotropical cervidology: biology and medicine of Latin American deer FUNEP-IUCN, Jaboticabal, Brazil, pp 89-100

Villero D, Pla M, Camps D, Ruiz-Olmo J, Brotons L (2017) Integrating species distribution modelling into decision-making to inform conservation actions. Biodiv Conserv 26:251-271

Zhao M, Running SW (2010) Drought-induced reduction in global terrestrial net primary production from 2000 through 2009. Science 329:940-943

Zheng H, Shen G, Shang L, Lv X, Wang Q, McLaughlin N, He X (2016) Efficacy of conservation strategies for endangered oriental white storks (Ciconia boyciana) under climate change in Northeast China. Biol Conserv 204:367-377

Zomer RJ, Trabucco A, Bossio DA, Van Straaten O, Verchot LV (2008) Climate change mitigation: a spatial analysis of global land suitability for clean development mechanism afforestation and reforestation. Agric Ecosyst Environ 126:67-80

\section{Submit your manuscript to a SpringerOpen ${ }^{\mathcal{O}}$ journal and benefit from:}

- Convenient online submission

- Rigorous peer review

- Open access: articles freely available online

- High visibility within the field

Retaining the copyright to your article

Submit your next manuscript at $>$ springeropen.com 